\title{
Selective Au Electrodeposition on Au Nanoparticles Embedded in Carbon Film Electrode for Se(IV) Detection
}

\author{
Shunsuke Shiba, ${ }^{1}$ Shota Takahashi, ${ }^{1}$ Tomoyuki Kamata, ${ }^{2}$ \\ Hiromitsu Hachiya, ${ }^{3}$ Dai Kato, ${ }^{2}$ and Osamu Niwa ${ }^{1 *}$ \\ ${ }^{1}$ Advanced Science Research Laboratory, Saitama Institute of Technology (SIT), \\ 1690 Fusaiji, Fukaya, Saitama 369-0293, Japan \\ ${ }^{2}$ National Institute of Advanced Industrial Science and Technology (AIST), \\ 1-1-1 Higashi, Tsukuba, Ibaraki 305-8566, Japan \\ ${ }^{3}$ Development \& Technology Division, DKK-TOA Corporation, \\ 613 Kita-iriso, Sayama, Saitama 350-1388, Japan
}

(Received November 29, 2018; accepted January 7, 2019)

Keywords: selenium(IV) detection, gold nanoparticle, electrodeposition, anodic stripping voltammetry, sputtered carbon film electrode

We report the ppb level detection of selenium by anodic stripping voltammetry (ASV) using finely dispersed gold nanoparticles (grown Au NPs) electrodeposited on sputter-deposited $\mathrm{Au}$ NPs embedded in carbon film electrodes. The Au NP-embedded carbon (AuNP-C) films were fabricated by the unbalanced magnetron (UBM) cosputtering of $\mathrm{Au}$ and carbon targets. The difference in overpotential between gold and carbon surfaces allows the selective deposition of gold ions only on the exposed Au parts of a AuNP-C film. As a result, we could successfully realize the highly dense deposition of Au NPs at the electrode surface without forming a $\mathrm{Au}$ film. By ASV with the developed electrode, we successfully increased the stripping current of selenium while maintaining the stable response derived from selectively grown $\mathrm{Au} \mathrm{NP}$ structures.

\section{Introduction}

Selenium is an essential element present in food, biological, and environmental systems. The beneficial effects of the dietary intake of selenium on human health have been confirmed, including anticancer effects, antiviral effects, the enhancement of immune response, the improvement of sperm mobility, and so on. ${ }^{(1,2)}$ However, it is also known that the concentration range between the beneficial effect and the toxicity of selenium is very narrow $(50-220 \mu \mathrm{g} / \mathrm{day}){ }^{(3)}$ Excessive levels of selenium intake cause selenosis, the symptoms of which are hair or nail loss, nail abnormalities, decayed teeth, skin lesions, and changes in peripheral nerves. ${ }^{(4)}$ On the other hand, inadequate levels of intake are associated with Keshan disease, Kaschin-Beck disease, and possibly several kinds of cancer. ${ }^{(4)}$

Selenium forms four oxidation states, namely, selenide [Se(II)], selenium [Se(0)], selenite $[\mathrm{Se}(\mathrm{IV})]$, and selenate $[\mathrm{Se}(\mathrm{VI})]$. Among these species, $\mathrm{Se}(\mathrm{IV})$ and $\mathrm{Se}(\mathrm{VI})$ are soluble in 
water, and Se(IV) exhibits a 5-10-fold higher toxicity than Se(VI). ${ }^{(3,5)}$ Therefore, the Se(IV) concentration in environmental and drinking water should be strictly monitored. In fact, the World Health Organization (WHO) regulates the selenium concentration in drinking water to less than $10 \mathrm{ppb}$.

The electrochemical determination of selenium has been preferably carried out compared with a conventional mass-spectrometry-based method because it is simple, inexpensive, and easy to use, and it exhibits the capability of a miniaturized device suitable for on-site analysis. In addition, electroanalysis can discriminate selenium with a different oxidation state by utilizing the difference in electrochemical activity between $\mathrm{Se}(\mathrm{IV})$ and $\mathrm{Se}(\mathrm{VI}),{ }^{(5)}$ which conventionally requires a chromatographic system coupled with, for example, inductive coupled plasma mass spectrometry ${ }^{(6,7)}$ and hydride generation atomic fluorescence spectrometry. ${ }^{(8,9)}$

The electrochemical method has been proposed on the basis of the anodic and cathodic stripping voltammetry of $\mathrm{Se}(\mathrm{IV})$, the oxidative detection of $\mathrm{Se}(\mathrm{IV})$ to $\mathrm{Se}(\mathrm{VI})$, and potentiometric stripping analysis. A mercury-film electrode (MFE) and a hanging mercury drop electrode $(\mathrm{HMDE})^{(10,11)}$ and its amalgam ${ }^{(12)}$ were utilized because they have a wide reductive potential limit and the ability to form alloys with target heavy metal ions, and they are less affected by electrode fouling. However, the toxicity of mercury itself required alternative electrode materials. A bismuth-based electrode can also be utilized for cathodic stripping voltammetry because it is environmentally friendly despite its similar physicochemical properties to a mercury-based electrode. In addition, low background noise current and low susceptibility to interference from dissolved oxygen contribute to improving the limit of detection for $\mathrm{Se}(\mathrm{IV})$ down to $0.1 \mathrm{ppb}(\sim 0.8 \mathrm{nM}) .^{(13,14)}$ However, the anodic potential limit of a bismuthbased electrode is relatively negative (at least less than $+0.2 \mathrm{~V}$ vs $\mathrm{Ag} / \mathrm{AgCl}$ ), which makes its application to selenium analysis based on anodic stripping voltammetry (ASV) difficult. ${ }^{(15)}$ In contrast, carbon-based electrodes including carbon nanomaterials such as reduced graphene oxide were also utilized. ${ }^{(16)}$ Although carbon materials are superior to a mercury-based electrode owing to its nontoxic nature and low background noise level, the lack of sensitivity limits the application of carbon electrodes to selenium analysis.

Gold-based electrodes have been regarded as the most suitable materials for selenium electroanalysis because of their nontoxic nature and ability to strongly adsorb selenium species $^{(17)}$ without modification by chelate species. ${ }^{(14)}$ In particular, gold nanoparticle (Au NP)-modified carbon electrodes have been extensively developed because of their higher sensitivity toward selenium analysis. Idris et al. reported the Au-NP-modified glassy carbon electrode for the electroanalysis of Se(IV) in water prepared by electrodeposition, successfully improving the limit of detection for selenium to less than $1 \mathrm{ppb}^{(18)}$ Ivandini and Einaga reported the detection of not only $\mathrm{Se}(\mathrm{IV})$ but also $\mathrm{Se}(\mathrm{VI})$, which has been considered as an electrochemically inactive species, by using a gold-modified boron-doped diamond electrode. ${ }^{(19)}$ Their reports indicate the usefulness of gold nanomaterials because of their electrocatalytic activity toward water-soluble $\mathrm{Se}(\mathrm{IV})$ and, maybe in the future, $\mathrm{Se}(\mathrm{VI})$ electrodeposition.

One of the problems in the case of using gold-based electrodes toward $\mathrm{Se}$ (IV) detection is that the electrodeposition mechanism is complicated. Several reports describe that, if an electrodeposition potential lower than around $-0.4 \mathrm{~V}$ vs $\mathrm{Ag} / \mathrm{AgCl}$ is applied in an acidic 
solution, the deposited selenium undergoes not only the simple reduction of adsorbed $\mathrm{Se}$ (IV) $\left(\mathrm{H}_{2} \mathrm{SeO}_{3}+4 \mathrm{H}^{+}+4 \mathrm{e}^{-}=\mathrm{Se}+3 \mathrm{H}_{2} \mathrm{O}\right)$ but also a further reduction reaction $\left(\mathrm{Se}+2 \mathrm{H}^{+}+2 \mathrm{e}^{-}=\right.$ $\mathrm{H}_{2} \mathrm{Se}$ ), leading to the loss of electrodeposited $\mathrm{Se}(0)$, which is not desirable from an analytical viewpoint. Moreover, $\mathrm{H}_{2} \mathrm{Se}$ could undergo a comproportionation reaction to $\mathrm{H}_{2} \mathrm{SeO}_{3}$ in a bulk solution $\left(\mathrm{H}_{2} \mathrm{SeO}_{3}+2 \mathrm{H}_{2} \mathrm{Se}=3 \mathrm{Se}+3 \mathrm{H}_{2} \mathrm{O}\right){ }^{(3,17)}$ Therefore, an applied potential higher than $-0.4 \mathrm{~V}$ is suitable for the analysis of $\mathrm{Se}(\mathrm{IV})$ to prevent the deposited $\mathrm{Se}(0)$ from further reduction reaction.

We previously reported the development of a Au-NP-embedded carbon film (AuNP-C) electrode for arsenic [As(III)] detection. ${ }^{(20)}$ Because of the low intermiscibility of carbon and gold phases, the cosputtering deposition of carbon and gold results in the formation of an atomically flat film electrode composed of dispersed $\mathrm{Au}$ NPs in the $\mathrm{sp}^{2} / \mathrm{sp}^{3}$ bond-hybrid carbon matrix. The developed electrode is characterized by higher sensitivity and stability toward arsenic [As(III)] analysis, which is derived from the small NP size $(<5 \mathrm{~nm})$ and tightly embedded structure, compared with the Au-NP-modified electrode prepared by physical adsorption. ${ }^{(20)}$ However, the sensitivity is low because the surface area of Au NPs exposed above the electrode surface is determined to be small by taking into account the lower deposition rate of selenium than of As(III). Therefore, both the electrocatalytic activity of $\mathrm{Au}$ NPs and a large active surface area are required to realize the highly sensitive detection of $\mathrm{Se}(\mathrm{IV})$, as described above.

Here, we report finely dispersed Au NPs electrochemically grown on a cosputterdeposited Au-NP-embedded carbon film (Au/AuNP-C) electrode. Owing to the difference in overpotential between carbon and Au NPs, we can electrodeposit gold ions preferentially on the Au NPs by controlling the electrodeposition potential (Fig. 1). We demonstrate that the proposed electrode material enabled us to improve the sensitivity and limit of detection for the stripping analysis of $\mathrm{Se}(\mathrm{IV})$.

\section{Materials and Methods}

\subsection{Apparatus}

All the electrochemical measurements were performed by using an electrochemical analyzer (CHI Instruments, Model 720e). A three-electrode configuration was set up throughout the

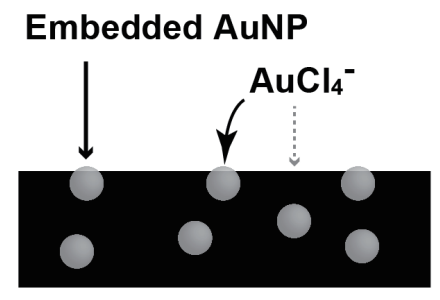

AuNP-C electrode

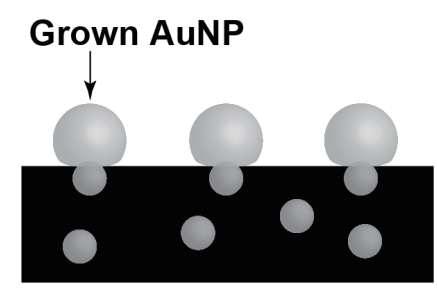

Au/AuNP-C electrode

Fig. 1. Selective electrodeposition of $\mathrm{AuCl}_{4}{ }^{-}$on Au NPs embedded in carbon film electrode. 
experiment with a $\mathrm{Ag} / \mathrm{AgCl}$ electrode $(3 \mathrm{M} \mathrm{NaCl})(\mathrm{BAS})$ and a $\mathrm{Pt}$ wire as reference and counter electrodes, respectively. High-resolution transmission electron microscopy (HRTEM) was performed using EM-002B high-resolution TEM (Topcon) with a point-to-point resolution of $0.23 \mathrm{~nm}$. Field emission scanning electron microscopy (FE-SEM) was carried out using a Model S-4800 (Hitachi High Technologies, Japan). All measurements were performed at room temperature.

\subsection{Materials}

Selenium standard solution (1000 ppm $\mathrm{H}_{2} \mathrm{SeO}_{3}$ dissolved in $1 \mathrm{M} \mathrm{HNO}_{3}$ ), gold standard solution $\left(1000 \mathrm{ppm} \mathrm{HAuCl}_{4}\right.$ dissolved in $\left.1 \mathrm{M} \mathrm{HCl}\right)$, and $1 \mathrm{M}$ sulfuric acid were purchased from Wako Pure Chemical Industries, Ltd. (Japan). Ultrapure water (Milli-Q) was used in all of the experiments.

\subsection{Film fabrication by cosputter deposition}

A Au-NP-embedded carbon film electrode and a pure carbon film (without Au NPs) were deposited on a boron-doped silicon (100) substrate formed by unbalanced magnetron (UBM) sputtering without heating as reported previously. ${ }^{(20,21)}$ The gold and sintered carbon targets were arranged to codeposit the sputtered atoms from each target on the substrate. No external substrate bias voltage was applied during sputter deposition, but a voltage of $-20 \mathrm{~V}$ was naturally generated in the substrate versus gold and carbon targets. This condition corresponds to the description "non-bias voltage" in a previous report, ${ }^{(22)}$ and the carbon film consists of an $80 \% \mathrm{sp}^{2}$ bond and a $20 \% \mathrm{sp}^{3}$ bond.

\subsection{Gold ion electrodeposition}

After cutting the film electrode into a rectangular shape, we put the insulating tape with a 2-mm-diameter hole on the deposited film electrode to define the electrode area $\left(0.0134 \mathrm{~cm}^{2}\right)$. For $\mathrm{Au}$ electrodeposition, we prepared the $\mathrm{AuCl}_{4}{ }^{-}$-dissolved solution from a commercial gold standard solution (Wako) by 10 -fold dilution with $0.1 \mathrm{M} \mathrm{H}_{2} \mathrm{SO}_{4}$. The $\mathrm{AuCl}_{4}{ }^{-}$dissolved solution finally consists of $100 \mathrm{ppm}(508 \mu \mathrm{M}) \mathrm{AuCl}_{4}{ }^{-}, 0.1 \mathrm{M} \mathrm{HCl}$, and $0.09 \mathrm{M} \mathrm{H}_{2} \mathrm{SO}_{4}$. We immersed the film electrode into the $\mathrm{AuCl}_{4}{ }^{-}$dissolved solution and applied potentials of $+0.65 \mathrm{~V}$ to the $\mathrm{Au}-$ NP-embedded carbon film electrode and $+0.50 \mathrm{~V}$ to the pure carbon film electrode for $240 \mathrm{~s}$. After washing the electrode surface with water, the electrode was transferred to the $1 \mathrm{M} \mathrm{H}_{2} \mathrm{SO}_{4}$ aqueous solution without drying and then initially cleaned electrochemically by potential scans from 0.1 to $1.5 \mathrm{~V}$ for 6 cycles.

\subsection{Structural characterization}

The internal nanostructure of the Au-NP-embedded carbon film electrode was observed by HRTEM. We prepared a sample for TEM observation by scratching the film from the Si 
substrate surface with a diamond pencil. The surface nanostructure of the grown Au-NPdeposited electrodes was characterized by FE-SEM. The number of grown Au NPs and their sizes were calculated by using Image $J$ software, a Java-based program provided by the National Institute of Health (NIH). The surface area of Au was estimated on the basis of reduction peak charges obtained by repeated cyclic voltammetry (CV for 6 cycles) in $1 \mathrm{M} \mathrm{H}_{2} \mathrm{SO}_{4}$ aqueous solution, which is the same process as electrochemical cleaning described above.

\subsection{Square-wave anodic stripping analysis of Se(IV)}

Square-wave anodic stripping voltammetry (SWASV) was performed for a Au-NPembedded carbon film electrode with or without $\mathrm{Au}$ electrodeposition and a commercial $\mathrm{Au}$ bulk electrode (BAS, Japan). The measurements consisted of three steps: (i) $60 \mathrm{~s}$ deposition at $-0.35 \mathrm{~V}$ vs $\mathrm{Ag} / \mathrm{AgCl}$ to preconcentrate $\mathrm{Se}(\mathrm{IV})$ while stirring a solution, (ii) square wave anodic stripping from +0.60 to $+1.50 \mathrm{~V}$ vs $\mathrm{Ag} / \mathrm{AgCl}$ using a frequency of $12.5 \mathrm{~Hz}$, an amplitude of $20 \mathrm{mV}$, and a step potential of $12 \mathrm{mV}$ after stirring a solution and waiting for $5 \mathrm{~s}$ at $+0.6 \mathrm{~V}$ vs $\mathrm{Ag} / \mathrm{AgCl}$, and (iii) $60 \mathrm{~s}$ potential application at $+1.40 \mathrm{~V}$ vs $\mathrm{Ag} / \mathrm{AgCl}$ to remove the remaining $\mathrm{Se}$ deposit from the gold surface.

\section{Results and Discussion}

\subsection{Nanostructures of AuNP-C electrode}

Figure 2 shows the TEM image of the AuNP-C electrode fabricated using UBM cosputtering equipment. A large number of black spots corresponding to AuNP-C were dispersed densely in the light gray region corresponding to the carbon matrix. The average size of Au NPs is around $2.6 \mathrm{~nm}$, which is highly uniform and almost equivalent to that of $\mathrm{Ni}-\mathrm{Cu}$ nanoalloy embedded in the carbon film electrodes fabricated using the same equipment as previously reported. ${ }^{(21)}$ Note that the size of the embedded Au NPs is twofold smaller than that of the Au NPs embedded in

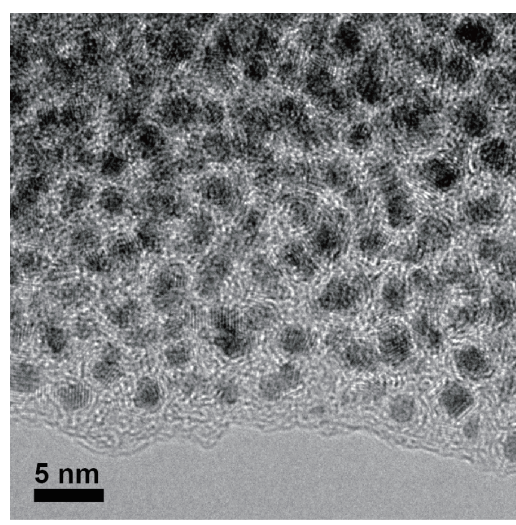

Fig. 2. Typical TEM image of Au-NP-embedded carbon film electrode. 
the carbon film electrode reported previously. ${ }^{(20)}$ This is probably because we use a different type of UBM sputtering equipment to deposit the films. The factors affecting the size of $\mathrm{Au}$ NPs could depend on the chamber shape and the distance between targets and a substrate.

\subsection{Electrode fabrication and characterization}

To obtain the suitable electrodeposition potential of Au ions only on the Au NP surface and not on the carbon surface, we investigated the difference in electrodeposition potential between the surfaces. Figure 3 shows the linear sweep voltammetry (LSV) results obtained by using carbon film electrodes with or without embedded Au NPs. The electrodeposition of Au ions at the AuNP-C film electrode was started at $+0.7 \mathrm{~V}$, which is $0.1 \mathrm{~V}$ more positive than that of the pure carbon film electrode (without Au NPs) because of the difference in overpotential between the carbon and Au surfaces. These results indicate that the selective electrodeposition of Au ions on only Au NPs exposed at the electrode surface can be achieved by controlling the electrodeposition potential $(+0.65 \mathrm{~V}$ vs $\mathrm{Ag} / \mathrm{AgCl}$ in this case).

Next, we investigated the surface morphology before and after Au electrodeposition. We conducted $\mathrm{Au}$ electrodeposition at $+0.65 \mathrm{~V}$ vs $\mathrm{Ag} / \mathrm{AgCl}$ for a $\mathrm{AuNP}-\mathrm{C}$ film electrode and at $+0.5 \mathrm{~V}$ vs $\mathrm{Ag} / \mathrm{AgCl}$ for the pure carbon film electrode. Figure 4 shows the SEM images of the $(a, b)$ AuNP-C film electrode and (c,d) pure carbon film electrodes with $(b, d)$ or without $(a, c)$ $\mathrm{Au}$ electrodeposition. Before electrodeposition, no structure was observed on both as-sputtered electrodes since these electrodes have atomically flat surfaces. ${ }^{(20-22)}$ After Au electrodeposition on the AuNP-C film electrode, numerous grown Au NPs (from 20 to $200 \mathrm{~nm}$, average diameter: $56 \mathrm{~nm}$ ) were observed. The density of grown Au NPs, which is calculated from the number of grown Au NPs divided by the observation area, is 71 nanoparticles $/ \mu \mathrm{m}^{2}$. In the case of electrodeposition on the pure carbon film electrode, a smaller number of spherical Au NPs

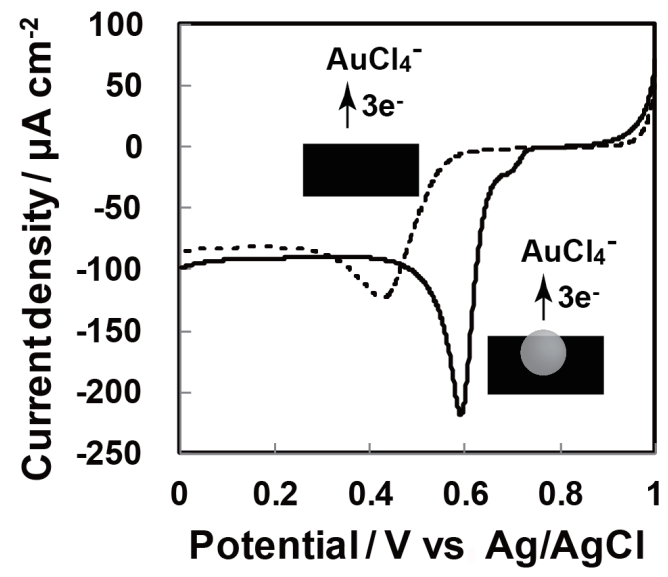

Fig. 3. Linear sweep voltammograms in $\mathrm{AuCl}_{4}{ }^{-}$dissolved solution with sputtered carbon film with (solid) and without (dotted line) embedded Au NPs. 


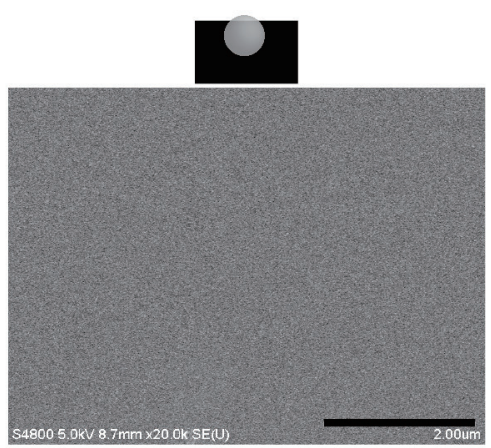

(a)

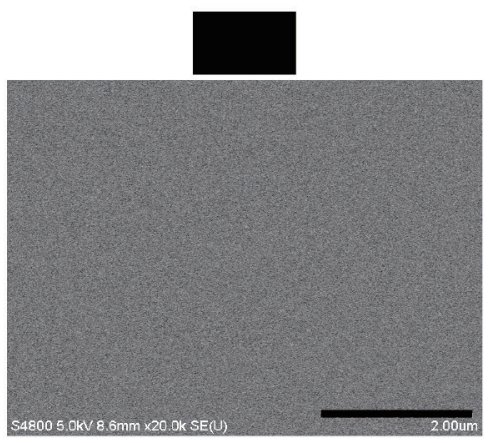

(c)

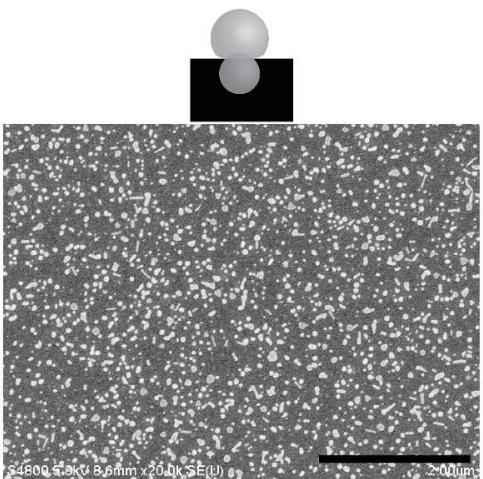

(b)

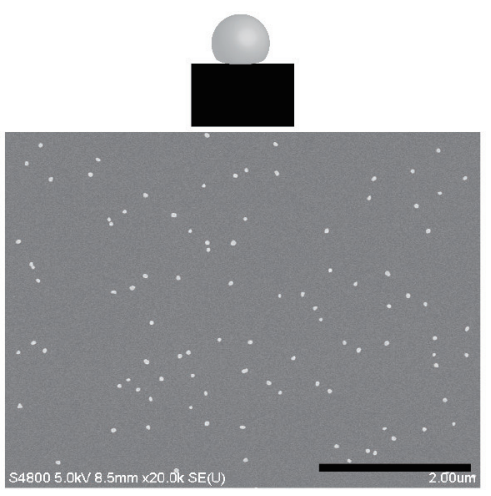

(d)

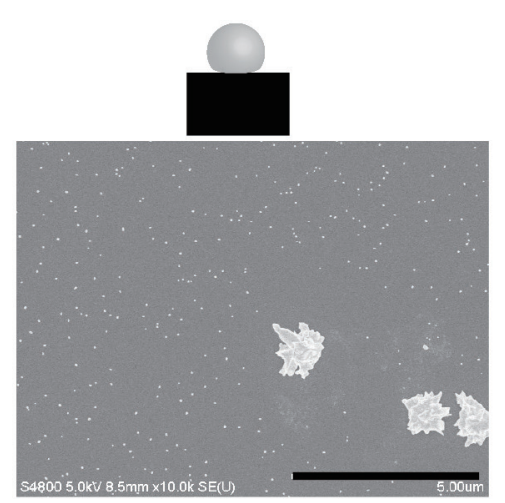

(e)

Fig. 4. SEM images of the (a and b) Au-NP-embedded carbon film electrode and (c-e) pure carbon film electrode (a and c) before and (b, d, and e) after $\mathrm{AuCl}_{4}{ }^{-}$electrodeposition. Scale bar: (a-d) $2 \mu \mathrm{m}$; (e) $5 \mu \mathrm{m}$.

$(\sim 62 \mathrm{~nm})$ were electrodeposited. The density is 17 -fold lower (4 nanoparticles/ $\left.\mu \mathrm{m}^{2}\right)$ than that on the AuNP-C film electrode owing to the lack of active sites for Au electrodeposition. Note that both spherical small Au NPs and flowerlike large Au aggregates $(\sim 1 \mu \mathrm{m})$ were observed at the pure carbon electrode with lower density $\left(0.005\right.$ nanoparticles $\left./ \mu \mathrm{m}^{2}\right)$ as shown in Fig. 4(e). No such large structure was observed at the Au/AuNP-C electrode. We previously reported that our sputter-deposited carbon film contains electroactive graphenelike nanocrystalline structure. ${ }^{(22,23)}$ We speculate that the more electroactive edge planes of the graphenelike nanostructure heterogeneously existing at the carbon surface may enhance the $\mathrm{Au}$ electrodeposition with a higher deposition rate, forming larger Au electrodeposits. In fact, such large Au electrodeposits were not observed at the Au/AuNP-C electrode surface because the electroactive Au NPs were homogeneously dispersed at the electrode surface, which is more suitable for Au electrodeposition. Also, it can be considered that large gold electrodeposits may result from the aggregation of small Au NPs electrodeposited on a carbon film surface. Such a phenomenon could be suppressed at the Au/AuNP-C electrode because the Au NPs at the bottom of the grown Au NPs are tightly embedded. Therefore, the grown AuNP-C could be tightly immobilized, suppressing the detachment and aggregation of electrodeposited Au NPs. 
To estimate the surface area of gold, we conducted the repeated $\mathrm{CV}$ (6 cycles) in $1 \mathrm{M} \mathrm{H}_{2} \mathrm{SO}_{4}$ aqueous solution. Figure 5(a) shows the cyclic voltammograms obtained using the AuNP-C film electrode before and after Au electrodeposition. Two small oxidation peaks at around +1.20 and $+1.35 \mathrm{~V}$, which correspond to two reduction peaks at around +0.95 and $+0.85 \mathrm{~V}$, respectively, were observed. These correspond to the oxidation and reduction of a gold surface with a different crystalline plane. After $\mathrm{Au}$ electrodeposition, both oxidation and reduction peaks became much larger while maintaining each peak potential. This result suggests the epitaxial growth of gold on the AuNPs. The reduction peak charges of AuNP-C and Au/AuNP-C, which are known to be proportional to the gold surface area at a ratio of $390 \mu \mathrm{C} \mathrm{cm}^{-2},(24,25)$ were $0.88 \mu \mathrm{C}\left(0.0023 \mathrm{~cm}^{2} \mathrm{Au}\right)$ and $2.95 \mu \mathrm{C}\left(0.0076 \mathrm{~cm}^{2} \mathrm{Au}\right)$, respectively. This resulted in a 3.4-fold increase in gold surface area. In contrast, Fig. 5(b) shows the cyclic voltammograms obtained using the pure carbon film electrode before and after Au electrodeposition. Before electrodeposition, no peak can be observed owing to the absence of gold species. After electrodeposition, a slightly broad oxidation peak at around $+1.2 \mathrm{~V}$ and two reduction peaks at around +1.0 and $+0.7 \mathrm{~V}$ were observed. The reduction peak charge is $1.07 \mu \mathrm{C}\left(0.0027 \mathrm{~cm}^{2} \mathrm{Au}\right)$, which is 3.5 -fold lower than that obtained using the Au/AuNP-C electrode $(2.95 \mu \mathrm{C} ; 0.0076$ $\mathrm{cm}^{2} \mathrm{Au}$ ). These results demonstrate that our proposed selective electrodeposition technique is effective for expanding the gold surface area while maintaining the shape of nanoparticles, which is very advantageous for the stripping analysis of metal ions. The reason why the 17fold higher density of grown Au NPs gave only a 3.3-fold larger gold surface area than that before electrodeposition is still unclear. We speculate that the observed larger gold aggregates $(\sim 1 \mu \mathrm{m})$ with a flowerlike structure on the pure carbon electrode contribute to the increase in electrochemically estimated gold surface area.

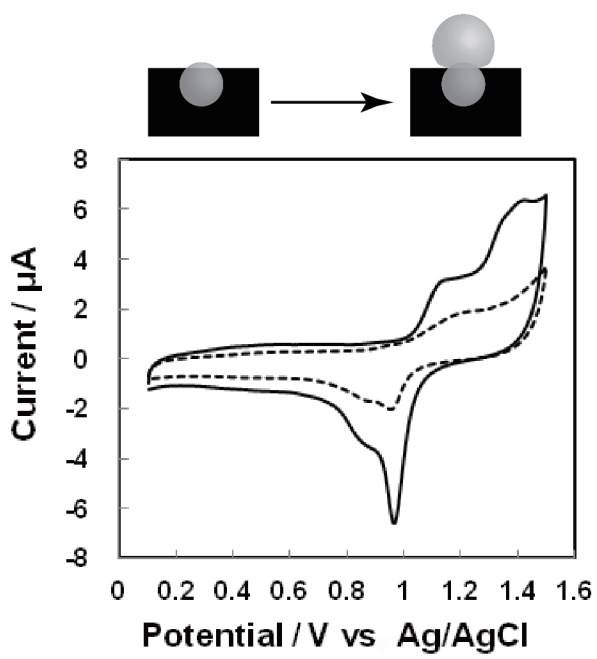

(a)

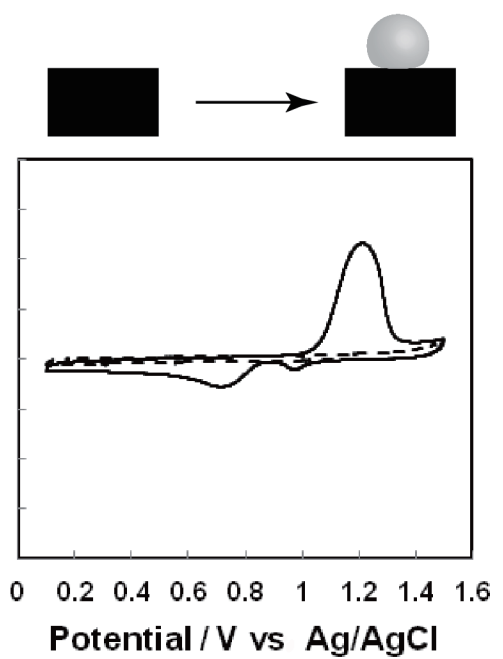

(b)

Fig. 5. Cyclic voltammograms obtained with (a) AuNP-C and (b) pure carbon films in $1 \mathrm{M} \mathrm{H}_{2} \mathrm{SO}_{4}$ aqueous solution before (dotted line) and after (solid line) Au electrodeposition ( $240 \mathrm{~s}$ ). Au deposition potentials are $+0.5 \mathrm{~V}$ for the pure carbon film electrode and +0.65 for the AuNP-C electrode. 


\subsection{SWASV of Se(IV)}

We applied our electrodes to Se(IV) electroanalysis. Figure 6 shows the SWASV curves of different Se(IV) concentrations obtained using AuNP-C, Au/AuNP-C, and (c) a commercial $\mathrm{Au}$ bulk electrode for comparison. The AuNP-C electrode gave small peak currents at around $0.92 \mathrm{~V}$ vs $\mathrm{Ag} / \mathrm{AgCl}$, which increased with the $\mathrm{Se}(\mathrm{IV})$ concentration. We could not detect $50 \mathrm{ppb}$ $\mathrm{Se}(\mathrm{IV})$. In contrast, the Au/AuNP-C electrode showed larger oxidation peak currents at around $0.91 \mathrm{~V}$ than the AuNP-C electrode, allowing the detection of a lower concentration of Se(IV) $(10 \mathrm{ppb})$ owing to the larger gold surface area. As shown in Fig. 6(c), the commercial Au bulk electrode could also detect $10 \mathrm{ppb}$ Se(IV). However, oxidation peak potentials positively shifted with increasing Se(IV) concentration from $0.83 \mathrm{~V}$ (for $10 \mathrm{ppb}$ ) to $0.89 \mathrm{~V}$ (for $1000 \mathrm{ppb}$ ). These results indicate that Au/AuNP-C exhibits a more stable electroanalytical performance than a conventional Au bulk electrode. We speculated that the difference in tendency is ascribed to the small nanoparticle size. It was already reported that the potential of the stripping peak is positively shifted by the formation of $\mathrm{Au}-\mathrm{Se}$ alloy. ${ }^{(3)}$ We expect that the $\mathrm{Se}(0)$ electrodeposited on the Au bulk electrode diffuses more deeply into the $\mathrm{Au}$ surface with increasing amount of deposited $\mathrm{Se}(0)$. On the other hand, the diffusion length of the electrodeposited $\mathrm{Se}(0)$ into the Au NPs is limited to the diameter of Au NPs, which is different from that of the Au bulk electrode. Therefore, we could obtain a stable stripping peak current without peak shift.

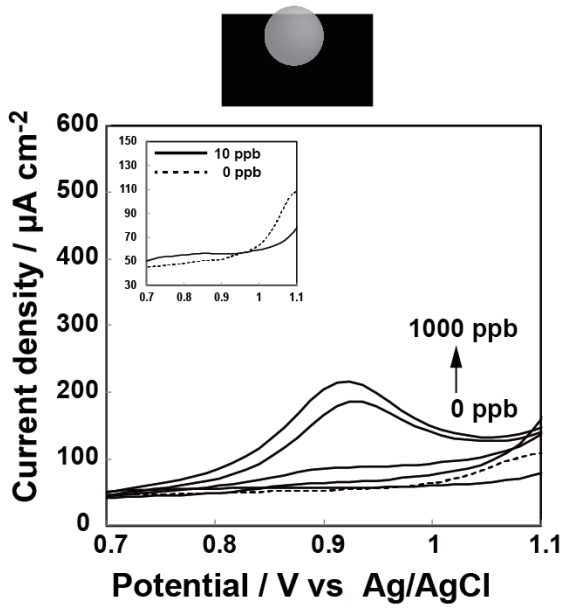

(a)

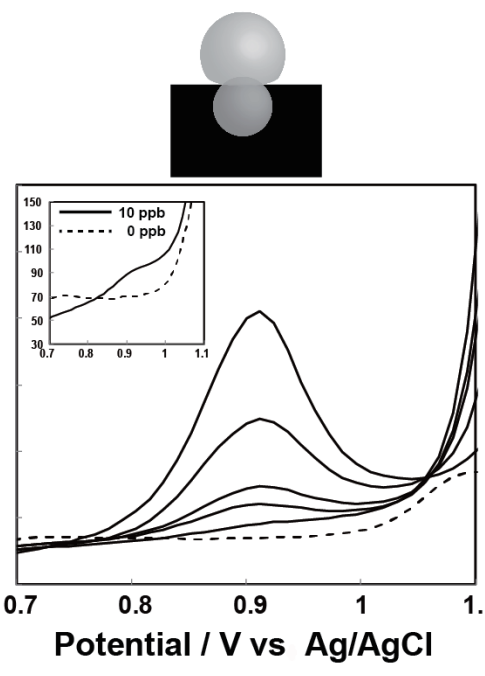

(b)

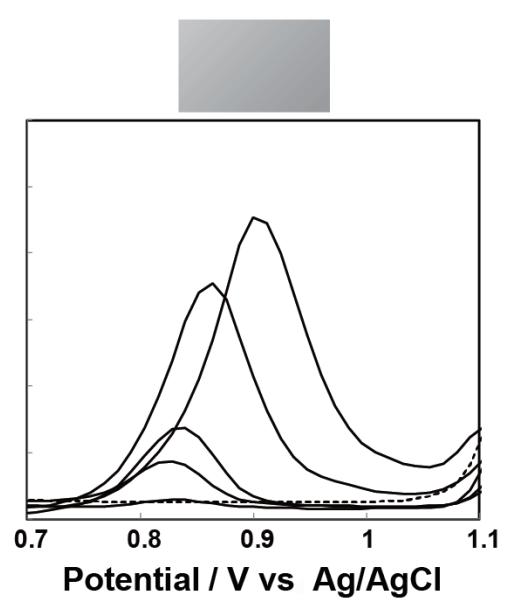

(c)

Fig. 6. SWASV curves of various Se(IV) concentrations before and after Au electrodeposition obtained using (a) AuNP-C, (b) Au/AuNP-C, and (c) Au bulk electrodes. $E_{d e p}=-0.3 \mathrm{~V}, t_{d e p}=60 \mathrm{~s}, f=12.5 \mathrm{~Hz}, E_{s w}=20 \mathrm{mV}$, and $\Delta E_{s}$ $=12 \mathrm{mV}$. Supporting electrolyte: $0.1 \mathrm{M} \mathrm{H}_{2} \mathrm{SO}_{4}$ aqueous solution. Se(IV) concentrations: 0, 10, 50, 100, 500, and $1000 \mathrm{ppb}$. The dotted line refers to the baseline [Se(IV) concentration $=0 \mathrm{ppb}$. Note that the obtained current is divided by the apparent electrode area $\left(0.0314 \mathrm{~cm}^{2}\right)$, not the gold surface area estimated electrochemically. Inset figures in (a) and (b) show magnified SWASVs of 0 and $10 \mathrm{ppb}$ Se(IV). 


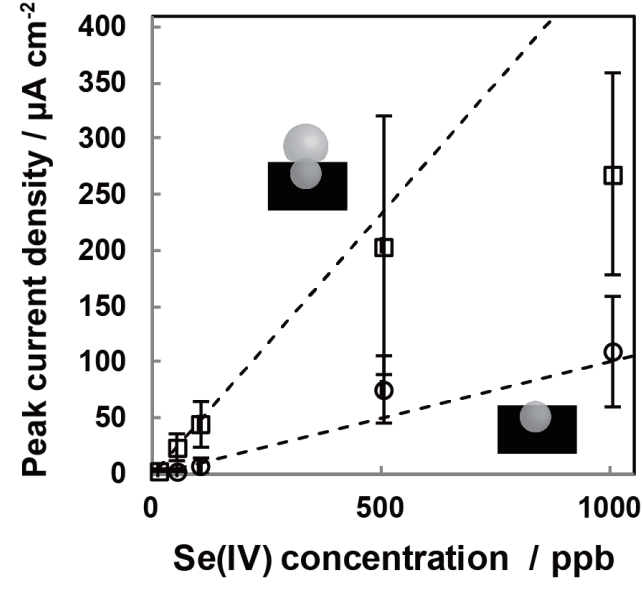

(a)

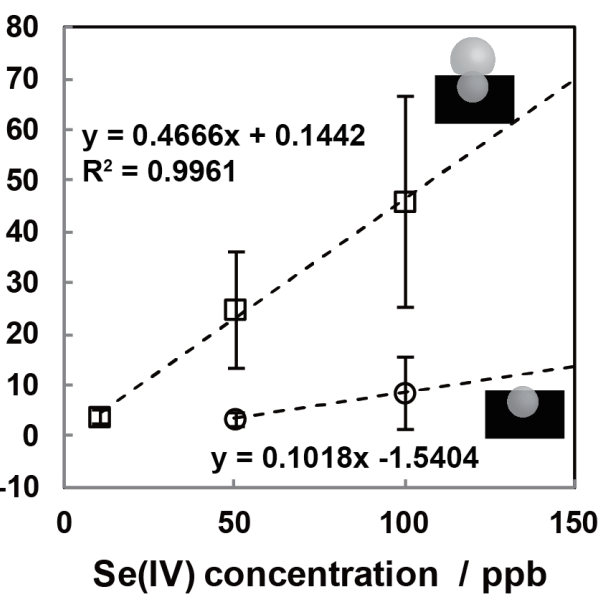

(b)

Fig. 7. Calibration plots [peak current height vs $\mathrm{Se}(\mathrm{IV})$ concentration] obtained with AuNP-C ( $\square$ ) and Au/ AuNP-C (o) electrodes with overall (a) and low (b) concentration regions (95\% confidence interval, $n=3$ ). Dotted lines correspond to approximate straight lines estimated from the plots shown in (b).

Figure 7 shows the calibration curves plotted from Fig. 6. The Au/AuNP-C electrode exhibits a 4.7-fold higher sensitivity $\left(0.47 \mu \mathrm{A} \mathrm{cm}{ }^{-2} \mathrm{ppb}^{-1}\right)$ than the AuNP-C electrode $\left(0.10 \mu \mathrm{A} \mathrm{cm}^{-2} \mathrm{ppb}^{-1}\right)$, which is in good agreement with the ratio of gold surface areas before and after $\mathrm{Au}$ electrodeposition (3.4×). We successfully improved the limit of detection of less than $10 \mathrm{ppb}$ for the Au/AuNP-C electrode, suggesting that the grown AuNP greatly improved the detection limit. This detection limit also means that the WHO's regulated levels of Se(IV) can be detected. These results indicate the importance of arranging numerous small $\mathrm{Au}$ NPs effectively on the supporting electrode for the stripping analysis of Se(IV). In addition, we performed a selectivity test and confirmed that the amount of $500 \mathrm{ppb} \mathrm{Cu}(\mathrm{II})$, a typical interfering substance for environmental Se(IV) detection, decreased in the stripping peak current of Se(IV) by $38 \%$ (Fig. A1). However, we found that the commercial chelex powders successfully removed only $\mathrm{Cu}(\mathrm{II})$ ions from the $\mathrm{Se}(\mathrm{IV})$ solution, fully recovering the stripping current of deposited Se(0) (Fig. A1). Therefore, we believe that such an appropriate pretreatment for removing interfering substances allows the practical application of our developed electrode to Se(IV) detection in food, biological, and environmental systems. To further optimize the electrode structure for analytical performance, we intend to control the size and density of $\mathrm{Au}$ NPs grown by changing the electrodeposition time and the number of embedded Au NPs in the near future.

\section{Conclusions}

We successfully fabricated selectively electrodeposited Au NPs on AuNP-C by a combined process based on cosputtering and electrodeposition techniques. Since the active sites (embedded $\mathrm{Au}$ NPs) of electrodeposition reaction were finely dispersed in advance, the deposited electrochemically grown Au NPs were also finely dispersed without forming a Au film. Our 
electrode gave a 3.3-fold higher gold surface area than that before electrodeposition. It became clear that the grown Au NPs give stripping currents without the potential shift induced by the increase in Se(IV) concentration, which is unlike the results obtained using a commercial Au bulk electrode. Our proposed methodology of electrode fabrication offers a better electrocatalytic interface suitable for the stripping analysis of both selenium ion and any other metal ions including arsenic ions.

\section{Acknowledgments}

This work was supported by the Saitama Prefectural Industry-Academia Collaborative Development Project Subsidy. Part of this work was conducted at the AIST Nano-Processing Facility, supported by the "Nanotechnology Platform Program" of the Ministry of Education, Culture, Sports, Science and Technology (MEXT), Japan.

\section{References}

1 L. C. Clark, G. F. Combs, Jr., B. W. Turnbull, E. H. Slate, D. K. Chalker, J. Chow, L. S. Davis, R. A. Glover, G. F. Graham, E. G. Gross, A. Krongrad, J. L. Lesher, Jr., H. K. Park, B. B. Sanders, Jr., C. L. Smith, and J. R. Taylor: JAMA 276 (1996) 1957. https://doi.org/10.1001/jama.1996.03540240035027

2 M. P. Rayman: Br. J. Nutr. 100 (2008) 254. https://doi.org/10.1017/s0007114508939830

3 V. Beni, G. Collins, and D. W. M. Arrigan: Anal. Chim. Acta 699 (2011) 127. https://doi.org/10.1016/ j.aca.2011.05.027

4 https://www.who.int/water_sanitation_health/water-quality/guidelines/en/(accessed 29 November 2018).

5 M. Grabarczyk and M. Korolczuk: J. Hazard. Mater. 175 (2010) 1007. https://doi.org/10.1016/ j.jhazmat.2009.10.110

6 M. Lenz, G. H. Floor, L. H. E. Winkel, G. Roman-Ross, and P. F. X. Corvini: Environ. Sci. Technol. 46 (2012) 11988. https://doi.org/10.1021/es302550b

7 M. Tie, B. Li, Y. Liu, J. Han, T. Sun, and H. Li: RSC Adv. 4 (2014) 62071. https://doi.org/10.1039/c4ra12975j

8 A. Castro Grijalba, E. F. Fiorentini, and R. G. Wuilloud: J. Chromatogr. A 1491 (2017) 117. https://doi. org/10.1016/j.chroma.2017.02.045

9 N. Zhang, L. Liu, W. Ren, and S. Chen: Determination of Selenium Species in Se-Enriched Food Supplement Tablets by Anion-Exchange Liquid Chromatography-Hydride Generation-Atomic Fluorescence Spectrometry: In Global Advances in Selenium Research from Theory to Application (CRC Press, London, 2016).

10 U. Baltensperger and J. Hertz: Anal. Chim. Acta 172 (1985) 49. https://doi.org/10.1016/s0003-2670(00)82592-1

11 P. Papoff, F. Bocci, and F. Lanza: Microchem. J. 59 (1998) 50. https://doi.org/10.1006/mchj.1998.1564

12 R. Piech and W. W. Kubiak: Electrochim. Acta 53 (2007) 584. https://doi.org/10.1016/j.electacta.2007.07.017

13 J. Long and Y. Nagaosa: Anal. Sci. 23 (2007) 1343. https://doi.org/10.2116/analsci.23.1343

14 Q. Zhang, X. J. Li, H. Shi, Hongzhou, and Z. B. Yuan: Electrochim. Acta 55 (2010) 4717. https://doi. org/10.1016/j.electacta.2010.03.068

15 A. Economou: Trac-Trends Anal. Chem. 24 (2005) 334. https://doi.org/10.1016/j.trac.2004.11.006

16 A. O. Idris, N. Mabuba, D. Nkosi, N. Maxakato, and O. A. Arotiba: Int. J. Environ. Anal. Chem. 97 (2017) 534. https://doi.org/10.1080/03067319.2017.1336233

17 M. Alanyalioglu, U. Demir, and C. Shannon: J. Electroanal. Chem. 561 (2004) 21. https://doi.org/10.1016/ j.jelechem.2003.07.016

18 A. O. Idris, N. Mabuba, and O. A. Arotiba: J. Electroanal. Chem. 758 (2015) 7. https://doi.org/10.1016/ j.jelechem.2015.10.009

19 T. A. Ivandini and Y. Einaga: Electrocatalysis 4 (2013) 367. https://doi.org/10.1007/s12678-013-0169-7

20 D. Kato, T. Kamata, D. Kato, H. Yanagisawa, and O. Niwa: Anal. Chem. 88 (2016) 2944. https://doi. org/10.1021/acs.analchem.6b00136

21 S. Shiba, D. Kato, T. Kamata, and O. Niwa: Nanoscale 8 (2016) 12887. https://doi.org/10.1039/c6nr02287a

22 T. Kamata, D. Kato, H. Ida, and O. Niwa: Diamond Relat. Mater. 49 (2014) 25. https://doi.org/10.1016/ j.diamond.2014.07.007 
23 R. Kurita, H. Yanagisawa, T. Kamata, D. Kato, and O. Niwa: Anal. Chem. 89 (2017) 5976. https://doi. org/10.1021/acs.analchem.7b00533

24 S. Trasatti and O. A. Petrii: Pure Appl. Chem. 63 (1991) 711. https://doi.org/10.1351/pac199163050711

25 L. D. Burke and P. F. Nugent: Gold Bull. 30 (1997) 43. https://doi.org/10.1007/bf03214756

\section{Appendix}

We performed a selectivity test by using a Au bulk electrode. Figure A1 shows SWASVs of $500 \mathrm{ppb} \mathrm{Se}(\mathrm{IV})$ with (black) or without (gray) $\mathrm{Cu}(\mathrm{II})$, which is known as one of the interfering substances in environmental samples from river and soils. The stripping current of $\operatorname{Se}(0)$ at around $0.85 \mathrm{~V}$ vs $\mathrm{Ag} / \mathrm{AgCl}$ was $38 \%$ decreased by adding $500 \mathrm{ppb} \mathrm{Cu}(\mathrm{II})$ ions to the $500 \mathrm{ppb}$ $\mathrm{Se}(\mathrm{IV})$ solution, suggesting that $\mathrm{Cu}(\mathrm{II})$ ions interfere with the $\mathrm{Se}(\mathrm{IV})$ detection. Then, we dispersed the commercial chelex powders $\left(\right.$ Chelex $^{\circledR} 100$ Chelating Resin, molecular biology grade, 200-400 mesh, sodium form, Bio-Rad Laboratories Inc.) in the mix solution of $500 \mathrm{ppb}$ $\mathrm{Se}(\mathrm{IV})$ and $500 \mathrm{ppb} \mathrm{Cu}(\mathrm{II})$ for removing only $\mathrm{Cu}(\mathrm{II})$ ions. After removing the chelex powders by ultrafiltration, we obtained the almost same SWASV as that in $500 \mathrm{ppb}$ Se(IV) standard solution, indicating that only $\mathrm{Cu}(\mathrm{II})$ ions could be selectively removed. As a result, we believe that some pretreatments for removing the interfering metal ions allow the practical application of our developed electrode to detect Se(IV) in real samples.

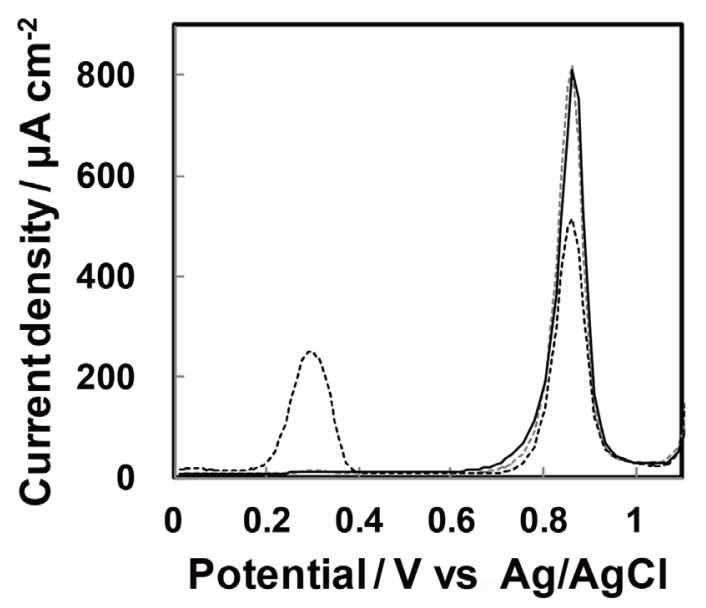

Fig. A1. SWASVs using a gold bulk electrode obtained from 500 ppb Se(IV) solution (gray dotted line), 500 ppb $\mathrm{Se}(\mathrm{IV})$ and $500 \mathrm{ppb} \mathrm{Cu}(\mathrm{II})$ mixed solution (black dotted line), and the mixed solution after dispersing and then removing chelex powders (black solid line). Chelex powders were dispersed in the solution containing $11 \mathrm{mM}$ $\mathrm{HNO}_{3}, 1 \mathrm{ppm} \mathrm{Se}(\mathrm{IV})$, and $1 \mathrm{ppm} \mathrm{Cu}(\mathrm{II})$ solution ( $\mathrm{pH}$ 2.7), and then the $\mathrm{pH}$ was adjusted to 0.7 by twofold dilution with $200 \mathrm{mM} \mathrm{H}_{2} \mathrm{SO}_{4}$ solution after ultrafiltration. SWASV conditions: $E_{d e p}=-0.3 \mathrm{~V}, t_{d e p}=60 \mathrm{~s}, f=12.5 \mathrm{~Hz}, E_{s w}=$ $20 \mathrm{mV}$, and $\Delta E_{s}=12 \mathrm{mV}$. 